\title{
Analisis Desain Excavator Bucket Menggunakan Metode Elemen Hingga dengan Material Baja
}

\author{
Agus Dwi Putra*, Mojibur Rohman, Abdul Wahab \\ ${ }^{a}$ Universitas Islam Raden Rahmat Malang, Jl. Mojosari No 2, Kec. Kepanjen, Kab. Malang, Kode Pos 65163 \\ *Corresponding author email: agusdput@gmail.com
}

\section{INFORMASI ARTIKEL ABSTRACT}

Diterima: 29 Agustus 2020

Direvisi: 31 Agustus 2020

Disetujui: 7 Oktober 2020

Tersedia online: 15 Oktober 2020

DOI:

doi.org/10.26905/jtmt.v16i2.4726

\begin{abstract}
This study aims to analyze the excavator bucket design with finite element method. The bucket design process was carried out using SolidWorks 2016 software. Finite element method analysis process was carried out using ANSYS 18.1 software in order to find von mises stress, displacement, strain, and safety factor in bucket design. The resultss show that the resultsing von mises stress is $7.72 \mathrm{~N} / \mathrm{m}^{2}$, the maximum strain on the bcket design is $2.25 \mathrm{~mm}$, and the resultsing strain is $2.08835 \mathrm{x} 106$ and the resultsing safety factor is 3.6.
\end{abstract}

Keywords: (Simulation, Finite Element Method, Bucket, Steel).

\section{A B S T R A K}

Penelitian ini bertujuan untuk menganalisis desain bucket excavator dengan metode elemen hingga. Proses desain bucket dilakukan dengan menggunakan software Solidworks 2016. Proses analisis metode elemen hingga dilakukan dengan memanfaatkan software ANSYS 18.1 guna untuk mencari von mises stress, displacement, regangan, dan safety factor pada desain bucket. Hasil menunjukkan bahwa von mises stress yang dihasilkan sebesar $7,72 \mathrm{~N} / \mathrm{m}^{2}$, regangan maksimum pada desain bucket sebesar $2,25 \mathrm{~mm}$, dan regangan terjadi sebesar 2,08835 x106 serta safety factor yang dihasilkan sebesar 3,6.

Kata Kunci: Simulasi, Metode Elemen Hingga, Bucket, Baja

2020 Unmer. All rights reserved

\section{Pendahuluan}

Desain dan kontruksi struktural mesin yang baik tidak akan diperoleh jika tidak mempelajari tentang ilmu kontruksi dan mekanika material. Suatu struktur tidak akan dapat diketahui kekuatannya tanpa melihat kondisi suatu bahan dan komposisi pembentuk struktur tersebut, sedangkan kekuatan dari bahan atau komposisi pembentuk struktur dapat diketahui dari data dan ilmu mekanika material yang telah berkembang [1].

Tugas perancang hanya tingal memilah-milah suatu material pembentuk struktur dengan tambahan ilmu mekanika material dan referensi peneliatan yang ada sehinnga suatu model dapat dibentuk dan dirancang sesuai keinginan yang ada [1].

Bucket adalah bagian dari Excavator yang bertugas menggaruk tanah atau material untuk dipindahkan dari tempat awal ke tempat tujuan. Kondisi tanah atau material tidaklah selalu rata dan gembur karena biasanya bercampur dengan material batu, pasir, dan logam. Pemilihan material sangat menentukan kinerja dari bucket agar bucket kuat dalam segala kondisi [2].

Salah satu logam yang kuat untuk dijadikan sebuah bucket adalah baja. Baja sudah banyak teruji dalam peralatan mekanik dan permesinan mulai digunakan dalam aplikasi rel kereta, piringan cakram, hingga bodi tank tempur Angkatan darat [3]. Pada penelitian ini akan dianalisis kekuatan dari baja tersebut untuk dijadikan material pembentuk bucket yang mana akan diaplikasikan dalam unit excavator. Analisis yang dilakukan adalah berupa simulasi kinerja dari bucket excavator yang mana simulasi berguna untuk menguji sauatu benda sebelum dapat diproduksi secara masal [4]. 


\section{Metode Penelitian}

Desain dalam pembuatan bucket dari excavator ini menggunakan software CAD yakni SolidWork 2016 serta menggunakan material ASTM A36 Steel. Adapun detail mengenai desain bucket dan material properties dapat dilihat pada gambar 1 dan tabel 1. Dapat diketahui bahwa perancangan desain dilakukan untuk menemukan gambaran desain yang akan dibuat [5]. Perancangan desain dilakukan setelah menemukan konsep desain yang tepat [6]. Perancangan desain perlu dilakukan sebelum pembuatan suatu objek [7].

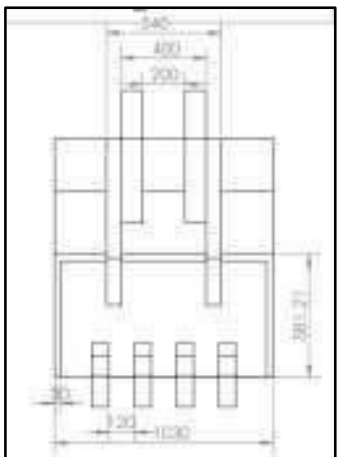

Gambar 1. Desain dua dimensi bucket

Tabel 1. Mateials Properties of ASTM Steel

\begin{tabular}{llll}
\hline No & Nama Material & \multicolumn{2}{c}{ Materials properties } \\
\hline 1 & ASTM Steel & Yoeld Strength & $2.5 \mathrm{e}+008 \mathrm{~N} / \mathrm{m}^{2}$ \\
\hline & & Tensile Strength & $4 \mathrm{e}+008 \mathrm{~N} / \mathrm{m}^{2}$ \\
\hline & & Elastic Modulus & $2 \mathrm{e}+011 \mathrm{~N} / \mathrm{m}^{2}$ \\
\hline & Mass Density & $7850 \mathrm{~kg} / \mathrm{m}^{3}$ \\
\hline 1 & Shear Modulus & $7.93 \mathrm{e}+010 \mathrm{~N} / \mathrm{m}^{2}$ \\
\hline & Poisson's Ratio & $\underline{0.26}$
\end{tabular}

Desain pada gambar 1 selanjutknya dianalisis dengan menggunakan metode elemen hingga. Proses analisis dengan mengandalkan Software ANSYS 18.1. Adapun desain tiga dimensi yang akan dianalisis dapat dilihat pada gambar 2 .

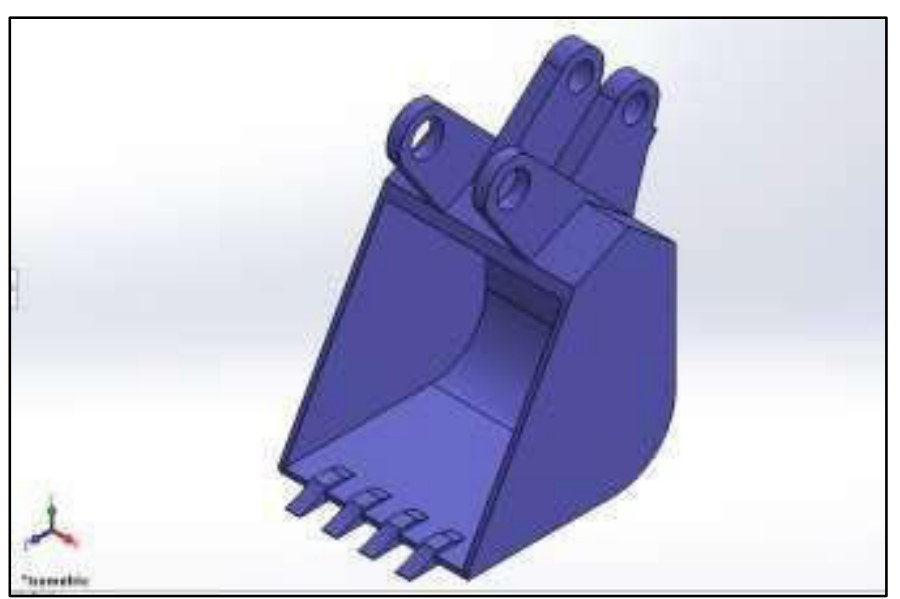

Gambar 2. Bentuk tiga dimensi dari Bucket

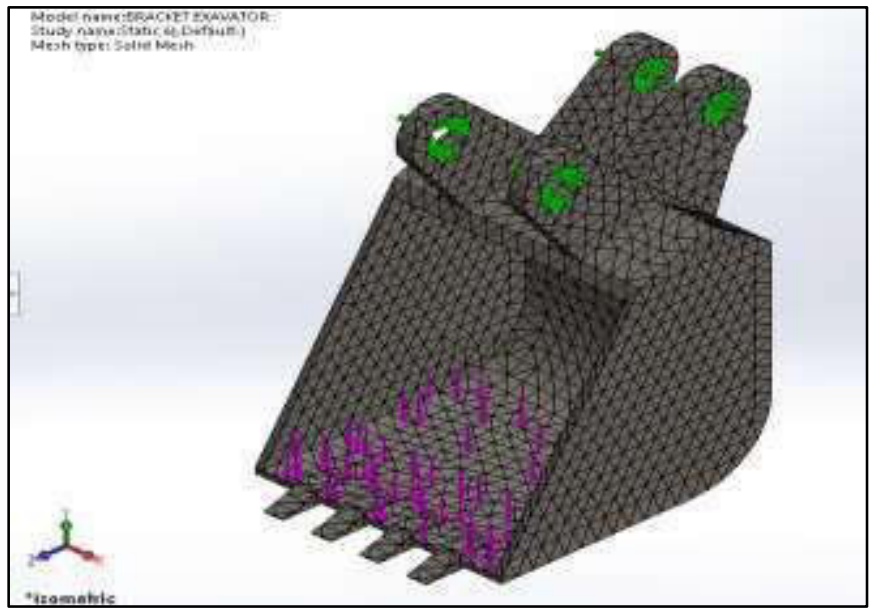

Gambar 3. Meshing desain Bucket

Setting meshing pada pengujian ini dengan menggunakan default setting yang mana dapat dilihat pada gambar 3 . Pengujian pada desain dilakukan dengan memberi tekanan atau gaya sebesar $1000 \mathrm{~N}$ pada ujung moncong bucket dan dianalisis untuk mengetahui Von mises stress, Displacement Pot, Regangan, dan Safety Factor dari desain bucket tersebut.

\section{Hasil dan Pembahasan}

\subsection{Hasil Von mises stress}

Hasil analisis menunjukkan bahwa dari sumulasi desain yang dilakukan didapatkan Von mises stress sebesar 7,72 $\mathrm{N} / \mathrm{m}^{2}$. Hasil tersebut dapat dilihat pada gambar 4 yang mana distribusi tegangan membentuk warana biru hingga merah dan terjadi dengan merata di bagian model. Pada bagian bawah tepatnya di sisi bawah "legend" dapat dilihat bahwa ada Batasan dari Yield Strength. Dari gambar 4 ini maka dapat diketahui perbandingan dari Von mises stress dengan yield strength apakah melebihi batas atau tidak [8].

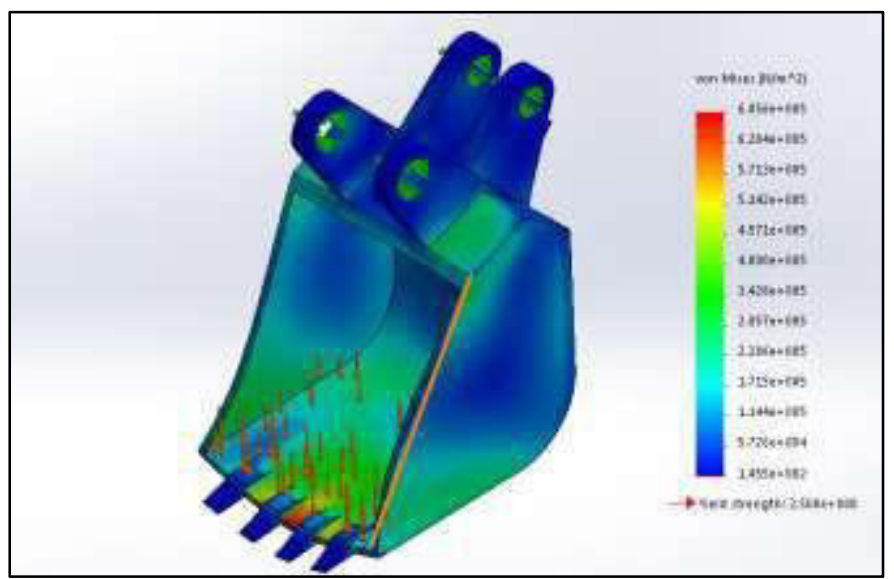

Gambar 4. Von mises stress

\subsection{Displacement Plot}

Berikut disajikan hasil analisis dari displacement plot yang mana displacement plot yang dihasilkan dari desain bucket sebesar 2,25 mm. Dalam Plot gambar 5 terlihat jumlah perbesarab distribusi de|eksi yang dialami suatu bucket. Dapat diketahui bahwa dari gambar 5 distribusi dari displacement atau deformasi yang ada terjadi pada 2 sisi bagain ujung bawah dari bucket. Displacement terjadi maksimum pada ujung moncong bucket karena pemuatan yang terus menerus 
TRANSMISI Volume 16 Nomor 22020

[9] akbiat beban yang besar serta ujung bucket termasuk komponen rawan terjadinya stress [10].

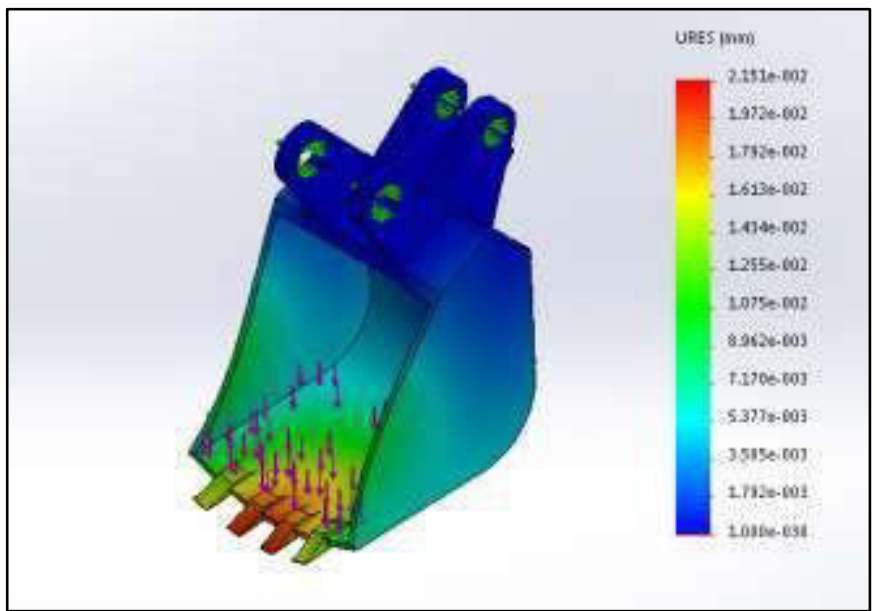

Gambar 5. Displacement Plot Results

\subsection{Strain Results}

Pada pembebanan yang dilakuakn pada desain bucket terjadi pertambahan panjang atau bisa disebut dengan regangan. Regangan terjadi akibat pemuatan beban yang terus-menerus [11] dan jika beban diberikan melebihi dari safety factor maka, akan terjadi crack (kegegalan material) [12]. Regangan maksimum yang dihasilkan dari desain bucket sebesar 2,08835 ×10 $\mathrm{mm}$ terjadi pada benda kerja dimana angka tersebut lebih rendah dari tegangan luluh yakni $2,5 \times 10^{8}$ $\mathrm{N} / \mathrm{m}^{2}$ sehingga masih aman untuk digunakan [13]. Regangan yang terjadi dapat dilihat pada gambar 6 .

Tabel 2. Hasil Analisis Simulasi

\begin{tabular}{llll} 
No & Simulasi & Nilai & Satuan \\
\hline 1 & Von mises stress & 7,72 & $\mathrm{~N} / \mathrm{m}^{2}$ \\
2 & Displacement & 2,2 & $\mathrm{~mm}$ \\
3 & Regangan & $2,08835 \times 10^{6}$ & $\mathrm{~mm}$ \\
4 & Safety factor & 3,6 & - \\
\hline
\end{tabular}

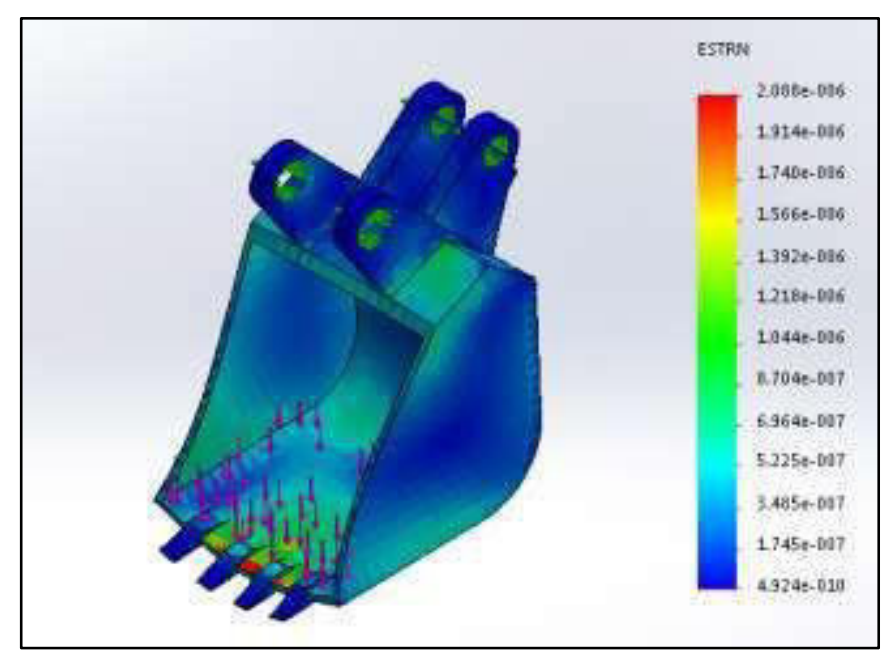

Gambar 6. Strain Resultss

\subsection{Plot FOS (Factor of Safety)}

Safety factor dalam bucket ini mengacu pada kekuatan material pembentuk dari bucket yang menerima tegangan setalah diberikan gaya atau beban sebesar 1000N. Dari perbandingan Allowable stress dan Von mises stress, maka dapat dekatahui distribusi dari Safety factor dalam bagian bucket [13]. Terlihat pada gambar 7 bahwa safety factor minimal yang dimiliki bucket adalah 3.6 dimana, model bucket tersebut compatible untuk dipergunakan.

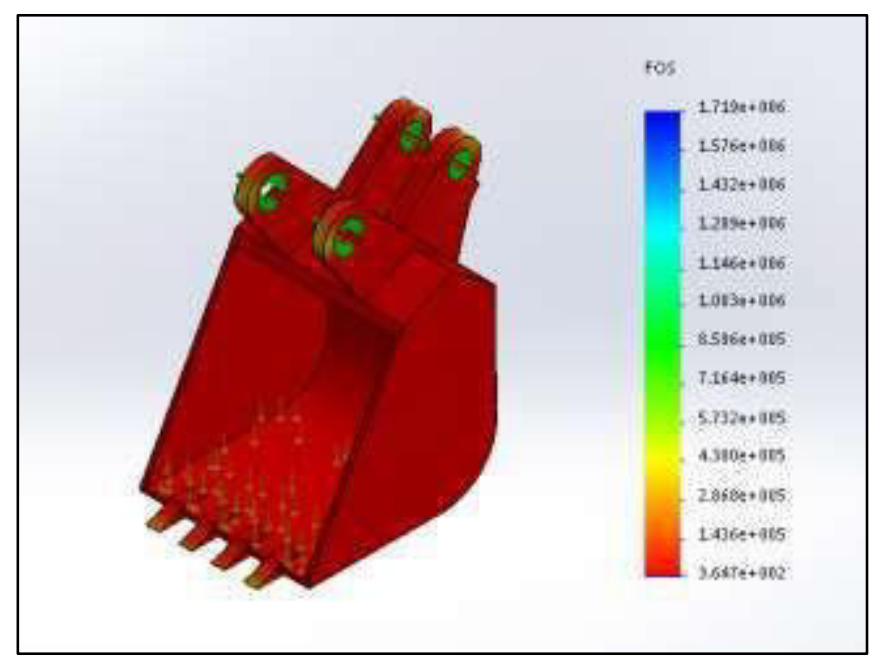

Gambar 7. Safety factor results

Keseluruhan hasil dari proses simulasi dapat dilihat pada tabel 2 yang mana, pada tabel 2 ini disajikan nilai dari analisis poin 3.1 hingga 3.4 .

\section{Kesimpulan}

Dari hasil simulasi yang telah dilakukan didapatkan bahwa desain bucket excavator dengan material ASTM Steel memiliki Von mises stress sebesar 7,72 N/m², Displacement sebesar 2,2 mm, dan regangan sebesar 2,08835 x10 $\mathrm{mm}$. Hasil analisis memenuhi kriteria bahwa desain bucket layak untuk diujicobakan dalam produksi prototype karena safatey factor yang didapatkan sebesar 3,6 sedangkan regangan yang dihasil jauh dari titik luluh atau dibawah tagangan luluh.

\section{Referensi}

[1] Y. Zhang, Y. Li, D. Su, and L. Jin, “Advanced flight control system failure states airworthiness requirements and verification," Procedia Eng., vol. 80, pp. 431-436, 2014, doi: 10.1016/j.proeng.2014.09.101.

[2] "Analisis kekuatan dan morfologi- Andoko AMSE TEMPLATE Post Review (revisi).”.

[3] M. S. Pham and S. R. Holdsworth, "Change of stressstrain hysteresis loop and its links with microstructural evolution in AISI 316L during cyclic loading," Procedia Eng., vol. 10, pp. 1069-1074, Jan. 2011, doi: 10.1016/j.proeng.2011.04.176.

[4] C. Seguin, G. Blaquière, A. Loundou, P. Michelet, and T. Markarian, "Unmanned aerial vehicles (drones ) to prevent drowning $\vec{s}$," Resuscitation, vol. 127, no. January, pp. 63-67, 2018, doi: 10.1016/j.resuscitation.2018.04.005.

[5] A. Ahmed, P. Hameed, F. Shaikh, Z. Hussain, N. Hussain, and M. Aslam, "Simulation tools application for arti fi cial lighting in buildings," Renew. Sustain. 
Energy Rev., no. August, pp. 0-1, 2017, doi:

10.1016/j.rser.2017.10.035.

[6] R. D. Perez, G. E. Falchini, F. C. Vincente, L. Soares, M. E. Poletti, and H. J. Sánchez, "A new XRF spectrometer using a crystal monochromator and parallel plates beam guides," Nucl. Instruments Methods Phys. Res. Sect. B Beam Interact. with Mater. Atoms, vol. 440, no. December 2018, pp. 4853, 2019, doi: 10.1016/j.nimb.2018.11.030.

[7] Andoko and P. Puspitasari, "Finite element analysis of surface tension on piston due to pressure variation," AIP Conf. Proc., vol. 1778, 2016, doi: 10.1063/1.4965798.

[8] R. V Fedorenko, A. A. Kudryavtsev, V. S, and I. R. Murtazin, "ScienceDirect ScienceDirect ScienceDirect Strength analysis of nuclear power plant structures in case of aircraft Strength analysis of nuclear power plant structures in Paço of aircraft crash impact crash impact modeling of a high a pressure turbine blade," Procedia Struct. Integr., vol. 6, pp. 244-251, 2017, doi:

10.1016/j.prostr.2017.11.037.

[9] J. W. Langelaan and E. Livne, “Analytic sensitivities and design oriented structural analysis for airplane fuselage shape synthesis," Comput. Struct., vol. 62, no. 3, pp. 505-519, 1997, doi: 10.1016/S00457949(96)00219-2.

[10] L. Witek, "Failure analysis of the wing-fuselage connector of an agricultural aircraft," Eng. Fail. Anal., vol. 13, no. 4, pp. 572-581, 2006, doi:

10.1016/j.engfailanal.2004.12.029.

[11] T. Itoh, M. Sakane, and K. Ohsuga, "Multiaxial low cycle fatigue life under non-proportional loading," Int. J. Press. Vessel. Pip., vol. 110, pp. 50-56, Oct. 2013, doi: 10.1016/j.ijpvp.2013.04.021.

[12] V. Infante, L. Fernandes, M. Freitas, and R. Baptista, "Failure analysis of a nose landing gear fork," Engineering Failure Analysis, vol. 82. pp. 554-565, 2017, doi: 10.1016/j.engfailanal.2017.04.020.

[13] S. Zameer and M. Haneef, "Fatigue Life Estimation of Artificial Hip Joint Model Using Finite Element Method," Mater. Today Proc., vol. 2, no. 4-5, pp. 2137-2145, 2015, doi: 10.1016/j.matpr.2015.07.220. 